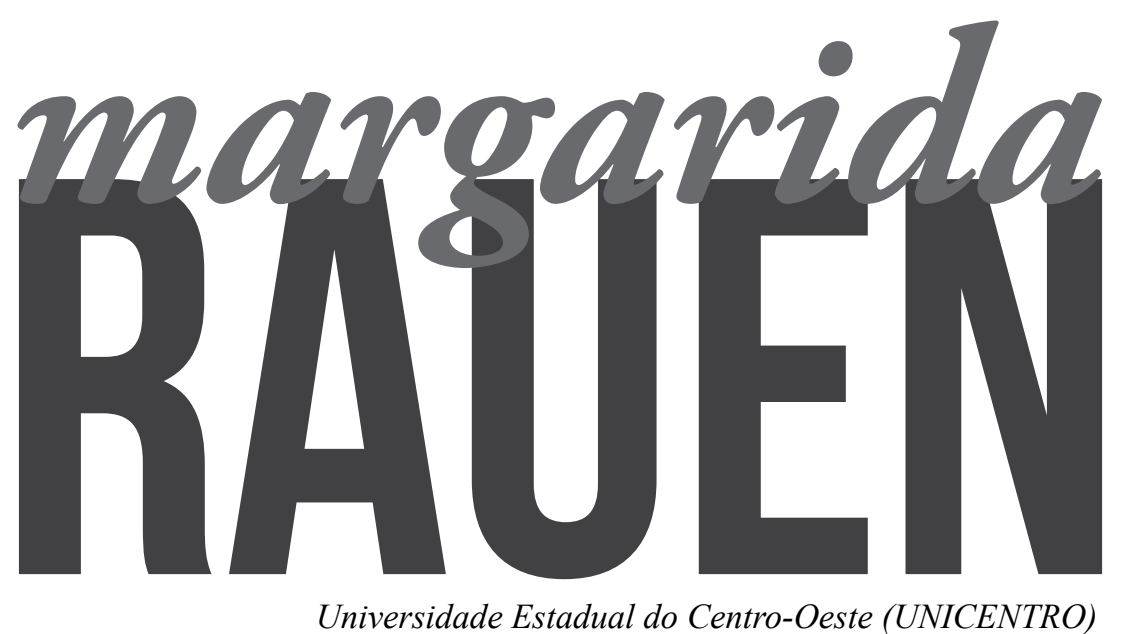

\title{
AS RESENHAS DE MONTAGENS DE PEÇAS DE SHAKESPEARE NO BRASIL
}

RESUMO> Este artigo aborda a recepção de montagens de peças de Shakespeare no Brasil. A escassez de resenhas durante o século XX é relacionada às políticas culturais de ditaduras, com as restriçóes à liberdade de expressão e à censura. Considera-se a predominância de críticos reacionários até os anos 1980 e o surgimento de reformistas, com abordagens interdisciplinares, nos anos 1980 . 


\section{AS RESENHAS DE MONTAGENS DE PEÇAS DE SHAKESPEARE NO BRASIL}

A premissa deste artigo é a de que na recepção das encenaçôes de peças de Shakespeare, no Brasil, o purismo foi predominante durante o final do século XIX e a primeira metade do século XX, e as abordagens reformistas ocorreram a partir dos anos 1980. Críticos puristas desconfiam das produçóes que transpóem os conteúdos universais e intemporais do cânone. Os reformistas tendem a apreciar positivamente as produçôes transpostas, que reavivam as dimensôes política e social de velhos temas. As abordagens radicais desestabilizam as universais e desconstroem relaçóes de poder. A escolha do texto sempre foi um aspecto crucial para os críticos que monumentalizam o poeta. $\mathrm{Na}$ medida em que os diretores optavam por versóes "verdadeiras" em língua portuguesa, escritas por tradutores que declaravam ter recriado o verso, os críticos elogiavam-nos por terem articulado a "essência" (um termo usado à exaustáo) dramática. Sem atenção alguma à história de transmissão, enfatizava-se a interpretação, o figurino e a cenografia, frequentemente apontandose a coerência com a época ficcional. Apesar disso, no contexto das ditaduras, a cobertura de aspectos formais sem muita preocupação em relação ao conteúdo foi uma característica marcante das posiçóes reacionárias.

O surgimento de contra-discursos que coexistiram com o essencialismo após os anos 1960 e a atual diversidade de modos relacionais na Internet, tais como sítios interativos e blogs de companhias de teatro que permitem, ao público, postar comentários, também transformaram os modos tradicionais de resenhar. Porém, não há estudos abrangentes dedicados à fortuna crítica do teatro Shakespeariano no Brasil, nem pesquisa substancial, por exemplo, abordando a existência de resenhas em periódicos. Os artigos e as outras fontes que selecionei, neste texto, então, são representativos

\footnotetext{
1 Professora da Universidade Estadual do Centro-Oeste Paraná. Ph. D. pela Michigan State University. Pós-Doutora pelo Folger Institute (Washington, D.C., 1993, 1998 e 2002).

E-mail: margie.g.rauen@gmail.com
} 
da escassa produção acadêmica sobre o assunto.

Um tema muito discutido é a escolha da tradução da peça a ser produzida, pois a transmissão por meio da traduçáo implica um interminável processo de reescritura. Marcia Martins, pesquisadora da história de tradução da obra de Shakespeare em português do Brasil, gerou um banco de dados contendo 172 títulos. Ao apresentar o sítio eletrônico, ela destaca a recomendação do crítico Eugênio Gomes, de “...que as traduçóes da obra de Shakespeare fossem refeitas periodicamente, como sucede em outros países [...] Segundo ele, cada geração precisa prestar essa homenagem ao poeta inglês."

Hamlet foi a primeira peça de Shakespeare traduzida ao português do Brasil, em 1933. Antes disso e durante o período colonial, as montagens eram encenadas por companhias que utilizavam versôes em português lusitano. João Caetano dos Santos (1835-1863), primeiro ator brasileiro a interpretar papéis shakespearianos, também utilizava traduçóes portuguesas. Os reconhecidos trabalhos de Pascoal Carlos Magno nos anos 1940, e do ator Sérgio Cardoso nos anos 1960, já contavam com versôes disponíveis em português do Brasil.

Numa retrospectiva anterior, afirmei que a atividade teatral mais antiga com peças de Shakespeare no Brasil encontra-se nos anos 1800 e antes da independência de Portugal, aos 1822 (RAUEN, 2001). José Roberto O’Shea (2005) confirmou essa data ao estudar João Caetano e argumentou que até mesmo o nosso principal crítico, Décio de Almeida Prado (1972), para o qual Caetano era uma celebridade, errou ao pressupor que ele interpretava peças traduzidas de edições inglesas: "Sob a influência do poeta e dramaturgo brasileiro Domingos José Gonçalves de Magalhães, Caetano, relativamente cedo em sua carreira, decidiu encarar o desafio de interpretar Otelo e Hamlet em traduções feitas pelo próprio Magalhães, não baseadas em Shakespeare, mas em Ducis”(O’SHEA, 2005, p. 29). O’Shea acrescenta que, em 1900, "Artur Azevedo, talvez o mais nacionalista dos críticos brasileiros, divulgou o seu repúdio ...” (O’SHEA, 2005, 
p. 35), acusando Caetano de náo ter produzido peças brasileiras, apesar de ter sido pago pelo Estado para trabalhar, preferencialmente, com dramaturgia nacional. Segundo O’Shea (2005), no entanto, Caetano interpretou muitas personagens criadas por dramaturgos brasileiros, bem como muitos outras por europeus. Esse cenário sugere a tendenciosidade de uma geração de críticos que abraçaram, no início do século $\mathrm{XX}$, uma política nacionalista, a qual piorou durante a ditadura de Getulio Vargas, quando as línguas estrangeiras foram banidas do currículo escolar por decreto.

Nesse contexto lusófono com uma mistura de influências francesas e inglesas, outra alteraçáo de perspectiva acontece com Eugênio Gomes (1961), considerado o mais antigo historiador da influência e transmissão da obra de Shakespeare no Brasil. Gomes chama a atenção por sua formação anglófona e quando se alinha com John Dover Wilson e William Hazlitt, entre outros (e incluindo os "New Critics"), defendendo pontos de vista essencialistas, tais como julgar o Rei Lear impróprio para o palco e enfatizar, em detrimento do aspecto cênico, o aspecto literário das peças. No capítulo "Hamlet através dos tempos", Gomes cita uma resenha escrita em 1907, por Pires de Almeida, para comentar a apropriação e a recepção de um Hamlet Shakespeariano e de outro por Ducis, em tradução de Oliveira Silva ao português (GOMES, 1961, p. 238). Conforme Gomes, João Caetano não foi bem sucedido quando montou o Hamlet de Shakespeare pela primeira vez, no Rio de Janeiro, em 1835. Vale citar toda a argumentação, na qual compara essa produção com a versão de Ducis, feita em 1840, também por João Caetano:

As nossas platéias não puderam sofrer a aspereza de Hamlet para com Ofélia, e que devia ser muito enfatizada naquela época, nem a vexatória situação entre mãe e filho e nem ainda a cena lúgubre e jocosa do cemitério. Cinco anos depois, o Hamlet de Ducis subiu à cena, também levado por João Caetano, e o mesmo público que tinha repelido a tragédia shakespeariana aplaudiu entusiàsticamente êsse arremêdo infeliz da grande peça. Em honra de nossa cultura, seja dito que o ator brasileiro não se conformava com êsse mau gosto de nossas platéias e, depois de certa altura, passara a representar 
alternadamente o Hamlet de Ducis e o de Shakespeare (GOMES, 1961, p. 238).

O trecho manifesta a preocupação de Gomes com os múltiplos modos de se encenar uma peça, caracterizando o seu ponto de vista anglófono e purista. No entanto, ele acredita que "Hamlet é afinal o protagonista-camaleão que toma sempre o colorido da terra por onde passa ..."(GOMES, 1961, p. 239). Com ironia, Gomes culpa Raymond Mander e Joe Mitchenson por não terem incluído, em sua antologia Hamlet Through the Ages [Hamlet através dos tempos] as produções realizadas por João Caetano e por Sérgio Cardoso. O discurso de Gomes não é consistentemente multicultural. Lembra o nacionalismo dos seus predecessores, mas em tom diferente, porque não foi motivado por xenofobia e sim por um desejo de inclusão no meio acadêmico anglófono.

Nos anos 1960, Barbara Heliodora projetou-se e o seu purismo despertou vários tipos de reação entre artistas do meio teatral. $\mathrm{O}$ valor histórico da sua breve retrospectiva de tradução e produção das peças de Shakespeare no Brasil (HELIODORA, 1967) é reconhecido por Martins (2008). Barbara Heliodora traduziu a obra completa de Shakespeare ao português e ainda escreve resenhas para o jornal $O$ Globo, no Rio de Janeiro.

Em 1965, Celuta Moreira Gomes e Thereza da Silva Aguiar organizaram uma bibliografia comemorativa dos 400 anos do aniversário de Shakespeare, publicada pelo Ministério de Educação e Cultura e Biblioteca Nacional, e refletindo o enorme interesse em Shakespeare no contexto da ditadura militar, iniciada em 1964. Dado o foco deste artigo, em crítica teatral, devo observar que essa publicação merece atenção por listar os diversos usos de obras de Shakespeare na produção cultural oficial durante o início do regime militar. Os verbetes incluem itens publicados exclusivamente em 1964, em 39 periódicos dos estados da Bahia, Minas Gerais, Rio de Janeiro, Rio Grande do Sul, Paraná, Pará, Pernambuco e São Paulo, embora a fonte da maioria dos itens seja os grandes jornais de São 
Paulo (Folha de S. Paulo e O Estado de Sáo Paulo) e do Rio (Correio da Manhã, Jornal do Brasil e O Globo). O volume contém fotografias em preto e branco das produçôes, muitas das quais mostram Sérgio Cardoso em dezenove papéis de Hamlet, na curiosa obra "O resto é silêncio", descrita como uma projeção de slides sobre Shakespeare (onde ele viveu pessoas importantes da época, artistas famosos que interpretaram as suas personagens, fac-símiles de algumas edições antigas de suas obras), narrada por Sônia Oiticica. Segundo GOMES e AGUIAR "Sérgio Cardoso interpreta 19 personagens usando 14 diferentes trajes, além de máscaras, perucas e outros adereços” (1964, p. 101). A bibliografia contém três relatos de montagens e uma resenha de autoria de Décio de Almeida Prado (1964), cuja anotação do verbete 181 segue:

'O resto é Silêncio' se não é a mais exata e nem a mais penetrante exégese shakespeariana que ouvimos neste ano do quarto centenário de nascimento do poeta, talvez seja a que maior prazer proporciona e mais fascínio exerce sobre o público, pela conjunção, hàbilmente feita e cuidadosamente preparada, de elementos visuais e auditivos. Publicado com as iniciais D.A.P. (GOMES e AGUIAR, 1965, p. 103).

Independentemente do que um crítico diria durante os anos de censura, a citação sugere a ironia de Prado ao tratar das produçôes relacionadas às comemoraçóes do aniversário de 400 anos de Shakespeare. Vários itens cobrindo produçôes de 1964, no Brasil e no exterior, tais como óperas, ballets, obras de cinema, rádio, televisão e discos de vinil são listados no corpo do volume, numa sessão denominada "Representações" (GOMES e AGUIAR, 1965, pp. 53-172). Numa única página que antecede essa grande sessão, contendo os títulos "IV. PARÓDIAS 1. COMENTÁRIO E CRÍTICA" segue a frase: "Nada foi publicado neste setor no ano de 1964." (GOMES e AGUIAR, 1965, p. 51).

Assim, a linha "O resto é silêncio" serve de epitáfio para as diversas décadas de censura que marcaram tanto os processos 
de criação quanto a fortuna crítica de teatro entre 1964 e os anos 1990. A liderança de Augusto Boal na cena pós-colonialista é tão incontestável quanto a estética do Teatro do Oprimido. Marlene Soares dos Santos discutiu o trabalho de Boal com o teatro de Arena de São Paulo, de 1956 a 1964 (antes do golpe militar) e de 1964 a 1971:

Por oito anos, Boal e o Arena puderam experimentar, desenvolver e tornar realidade a idéia de um teatro nacional, com uma voz popular que buscava tornar o público politicamente esclarecido o encorajava a acreditar em seu poder de mudar o status quo [...] depois do golpe, o Arena teve que encontrar um jeito de burlar a censura (SANTOS, 2002, pp. 47-48).

$\mathrm{Na}$ continuação do artigo, Santos (2002) considera a recepção de $A$ Tempestade (1981), de Augusto Boal, uma paródia de $A$ Tempestade, de Shakespeare, que também implica o conflito entre pontos de vista puristas e reformistas. Assim como o crítico Flávio Marinho rejeita a ideia de paródia, definindo-a como uma tempestade pobre (quando comparada à tempestade mágica de Shakespeare), o crítico Yan Michalsky argumenta que a diferença entre Shakespeare e Boal “... precisa ser percebida” (SANTOS, 2002, p. 52). Boal foi aluno de John Gassner na Universidade de Columbia, em New York, e associou-se ao Grupo de Escritores do Brooklyn [Brooklyn Writer's Group] em 1954, respondendo a um convite de Langston Hughes, o qual ele menciona com especial apreço em sua autobiografia (BOAL, 2000). Nela, Boal autodenominase um "homem de Columbia" (BOAL, 2000, p. 176), desejando pensar grandes obras e ao mesmo tempo descrevendo a sua missão conflituosa de assumir uma posiçáo contra o colonialismo cultural. Essa é a diferença que deve ser considerada em sua Tempestade, uma peça que desestabiliza um ícone cultural, como tantas paródias.

Roberto Rocha escreveu um notável ensaio sobre uma produção de Coriolanus, de 1974, com o falecido ator Paulo Autran e dirigida por Celso Nunes, argumentando que 
a censura, embora não tão rígida quanto no período 1969-70, logo depois que o AI-5 foi promulgado, em 13 de dezembro de 1968, ainda era muito severa com a produção cultural [...] Qualquer notícia prejudicial à boa imagem do governo não podia ser publicada ou veiculada (ROCHA, 2005, p. 37).

O diretor Celso Nunes era, tecnicamente, dedicado à “... vanguarda teatral internacional. Ele obteve a graduação em Direção na Sorbonne [e foi] influenciado pelo expressionismo alemão, por Antonin Artaud e Jerzy Grotowsksi” (ROCHA, 2005, p. 44). Embora Nunes tenha experimentado essas escolhas estéticas modernistas, a produção não apresentou uma abordagem radical ao conteúdo e "... náo alcançou o objetivo de criticar o regime" (ROCHA, 2005, p. 50). Parece que esse resultado foi conveniente para evitar a censura e conseguir autorização de abertura da bilheteria.

Vale enfatizar que, antes de estrear uma peça, as companhias tinham de apresentá-la a um comitê de censura. Um censor podia simplesmente proibir a peça ou impor cortes e alteraçóes antes de liberá-la para o público, e nenhum evento de entretenimento era lançado sem liberação oficial. Maria Cristina Costa oferece uma ampla discussão desse período complexo da história do Brasil (COSTA, 2006). Mais de 500 peças, 600 filmes e milhares de cançóes, livros e outros produtos culturais foram proibidos entre 1968 e 1978, quando o AI-5 passou a vigorar, mas a prática da censura continuou até 1988, quando foi promulgada a nova Constituição, com o seu simbólico quinto artigo garantindo a liberdade de pensamento e da imprensa. Em resumo, quando uma peça como o Coriolanus, de Nunes, era liberada por um agente de censura, quaisquer conteúdos relacionados à história política brasileira tinham sido cortados. Além disso, com a censura à imprensa, quaisquer textos de um crítico também eram limitados pela ação de agentes de censura que supervisionavam jornais, revistas e livros, inclusive os traduzidos. Portanto, indícios de valor inestimável para os estudos de recepção não estão disponíveis. 
Surgiram diversas visões teóricas pertinentes à explicação das decisões de tradução e de suas tensões durante o século XX. O assunto continuou recebendo atenção acadêmica em muitos idiomas. Exemplos lusófonos adicionais e representativos são os ensaios da antologia organizada por Rui Carvalho Homem e Ton Hoenselaars (2004). A principal questão que ocupa os autores está relacionada às circunstâncias da recepção no campo da tradução, com aspecto adicional na crítica teatral e sob duas perspectivas: de um lado, há os defensores do Shakespeare verdadeiro, com seus discursos de fidelidade ao texto na página e na encenação; de outro lado, há quem busque a equivalência cultural, assim como o fazem muitos diretores teatrais e críticos. Enquanto o primeiro grupo implica uma abordagem filológica, o segundo geralmente propõe a lógica de transposição na cena e tem um foco nos públicos, até mesmo envolvendo o trabalho colaborativo entre diretores e tradutores, com um público alvo em mente. As análises dessa tensão têm enfatizado dicotomias, tais como purismo $\mathrm{X}$ reformismo, e essencialismo $\mathrm{X}$ revisionismo. Enquanto alguns buscam uma encenação Platônica, afirmando a fidelidade ao que Shakespeare teria escrito (ironicamente, na mediação de um tradutor) e outros defendem a liberdade do diretor para transpor as peças enfatizando os seus temas universais e intemporais, surgiu um terceiro grupo na crítica e na encenação, com atitudes pós-coloniais de apropriação, produção e recepção.

Em minha experiência como correspondente para a Bibliografia Mundial de Shakespeare, de 1988 a 1998, resenhas críticas de peças teatrais eram raramente encontradas em periódicos brasileiros, especialmente quando comparadas à frequência de abordagens pós-coloniais de direção. Repórteres e críticos, se é que esses substantivos podem ser usados para definir profissóes reprimidas durante muitas décadas, frequentemente usam resenhas descritivas (também denominadas release em português) fornecidas por diretores de produção. Mantive, a convite do jornal $O$ Estado do Paraná, uma coluna de resenha teatral no início dos anos 1990, quando o Festival de Teatro de Curitiba foi lançado e despertou ampla cobertura de mídia. A liberdade de imprensa acabara de 
ser estabelecida na constituição de 1988 e um clima positivo instaurou-se, com os novos subsídios para as artes cênicas. Desde então, outros críticos projetaram-se, tais como Valmir Santos, Luiz Fernando Ramos e Mariângela Alves Lima. A habilidade dessas pessoas em analisar tanto a forma, quanto o conteúdo, e sua abertura para apreciar as produçóes evitando hierarquizá-las, enfatizando argumentos técnicos e conceituais ao invés do julgamento de valor, certamente indica uma mentalidade reformista.

Pesquisadores que realizaram os seus doutorados em literatura, dramaturgia e teatro nos Estados Unidos, no Reino Unido e no Brasil no final dos anos 1980 também acrescentaram uma nova dimensão ao campo quando fundaram o Centro de Estudos Shakespearianos (CESh), em 1991. Desde então, membros do CESh produziram obras críticas, sobre teatro como produto textual e como evento cênico (RESENDE, 2002; SANTOS e LEÃO, 2008; CAMATI e MIRANDA, 2009).

A crítica teatral na mídia tem recebido pouca atenção acadêmica no Brasil. Em sua maior parte, o trabalho dos colegas do CESh reflete diversas abordagens também familiares aos nossos pares anglófonos, em livros como Approaching Theatre, de André Helbo, J. Dines Johansen, Patrice Pavis e Anne Ubersfeld (1987). Da imensa bibliografia sobre performance studies, publicada nos últimos vinte e cinco anos, destaco esse livro por seu foco no teor interdisciplinar da teoria e da crítica, utilizando abordagens tão diferenciadas quanto a pesquisa empírica, os estudos históricos, a filosofia, a crítica de interpretação, a dramaturgia, a psicologia, os métodos sociológicos (em especial as entrevistas e surveys) e a semiótica.

Atualmente, as resenhas de pesquisadores do Brasil refletem essa diversidade de abordagens críticas e sugerem a sua formação anglófona, verificada nos ecos frequentes de Linda Hutcheon (2006), Margaret Kidnie (2009), Christy Desmet and Robert Sawyer (1999), Charles Morowitz (1991) e Helbo et al (1987). Um ponto de vista pós-colonial marca o meu próprio trabalho, $A$-tor-men-tado Calibanus, uma apropriação radical de The Tempest. As continuadas 
resenhas acadêmicas de Roberto Rocha abrilhantaram o estado da arte pertinente à recepção de Hamlet desde 1948, citando os críticos Aimar Labaki e Alberto Guzik. As diversas resenhas e artigos de Anna Stegh Camati também proporcionaram um acréscimo substancial às discussôes de apropriaçôes radicais das peças de Shakespeare no Brasil.

O assunto da fortuna crítica em periódicos provavelmente proporcionará conteúdos fascinantes para quem está disposto a buscar e descobrir periódicos em diversas bibliotecas. Uma hipótese óbvia é que resenhistas escreveram para os jornais e revistas e precisaram lidar com a dureza da censura, muito antes de as pesquisas acadêmicas sobre Shakespeare iniciarem nos anos 1960, quando Eugênio Ramos e Bárbara Heliodora projetaram-se. O impacto da censura e da política cultural do regime militar foram discutidos por muitos historiadores, embora estes náo escrevam especificamente sobre a fortuna crítica de produções Shakespearianas. Uma amostra desse imenso campo veio a público na coleção de 83 resenhas por Décio de Almeida Prado, com prefácio do Prof. João Roberto Faria (PRADO, 2002). Essas resenhas foram, originalmente, publicadas no jornal O Estado de São Paulo (1955-1964) e apenas duas se referem a produçóes de peças de Shakespeare: o Hamlet de Sérgio Cardoso (1956) e o Otelo de Adolfo Celi (1956). Prado não ficou satisfeito com as montagens, mas escreve com respeito e rigor técnico. Sobre Hamlet, enfatiza que

É a primeira tentativa profissional de montar Shakespeare em Sáo Paulo; a maioria do elenco tem menos de 25 anos; é, acima de tudo, uma produção extraordinariamente honesta [...] a pior falha da peça é não poder ser ouvida e claramente compreensível. A tradução de Péricles Eugênio da Silva Ramos é admiravelmente fiel [... mas] não muito teatral (PRADO, 2002, p. 22).

Em sua resenha do Otelo de Adolfo Celi, Prado entusiasmase com o fato de estarem acontecendo produções de Shakespeare no Brasil, mas observa, com rigor, o desequilíbrio entre a grande 
presença de Paulo Autran no papel principal e a interpretação tímida das personagens secundárias.

Para além das páginas de crítica em volumes de papel, está o universo de nossa era da Internet. Talvez a maior novidade seja que a primeira tradução ao português da edição mais antiga de Hamlet (1603), chamada in Quarto 1 (Q1), por José Roberto O'Shea, que ganhou uma leitura dramática no espaço alternativo de uma igrejinha que virou teatro na Universidade Federal de Santa Catarina, em Florianópolis (SHAKESPEARE, 2010). Uma notícia on-line mencionava que o elenco buscava a participação do público. Resenhas e notícias sobre festivais, temporadas de teatro e peças por todo o Brasil podem ser exploradas on-line. Embora o teor do material de Internet raramente seja crítico, a informação é aberta e pode conter depoimentos de atores e diretores, refletindo sobre o seu trabalho. Além disso, encontram-se as notícias internacionais de nossas produçóes, como o sucesso continuado do Grupo Galpão e da montagem do Romeu e Julieta no Festival Mundial de Shakespeare no Teatro Globe, em Londres, em maio de 2012.

Se Prado ficou satisfeito ao perceber que Shakespeare podia ser encenado no Brasil, quando resenhou o Otelo de Celi, há mais de meio século, alegra-me encerrar este artigo admitindo que a quantidade de produçóes de peças de Shakespeare no Brasil é muito maior do que se poderia imaginar, e ainda temos o reconhecimento conquistado por artistas brasileiros em eventos internacionais. Lamentavelmente, até o momento, ainda não temos um livro ou mesmo um catálogo sobre as resenhas de montagens de peças de Shakespeare no Brasil, um filão que também poderia ser aproveitado nas linhas de pesquisa de pós-graduação em artes cênicas, considerando a existência de outra geração de críticos desde os anos 2000 . 


\section{REFERÊNCIAS BIBLIOGRÁFICAS}

ALMEIDA, Barbara Heliodora C. de M. F. de. Shakespeare in Brazil. In: MUIR, Kenneth (ed.). Shakespeare Survey 20, Shakespearean and Other Tragedy. Cambridge, Cambridge University Press, 1967.

BOAL, Augusto. Hamlet e o filho do padeiro. Rio de Janeiro; São Paulo, Record, 2000.

CAMATI, Anna Stegh; MIRANDA, Célia Arns de (org.). Shakespeare sob múltiplos olhares. Curitiba, Ed. Solar do Rosário, 2009.

CAMATI, Anna Stegh. Sonho de Uma Noite de Verão: o Erudito e o Circense em Cena. In: CAMATI, Anna Stegh; MIRANDA, Célia Arns de (org.). Shakespeare sob múltiplos olhares. Curitiba, Ed. Solar do Rosário, 2009, pp. 269-290.

CAMATI, Anna Stegh. Hamletrash: A Brazilian Hamlet Made of Scraps. In: RESENDE, Aimara da Cunha (org.). Brazilian Readings of Shakespeare. Newark, University of Delaware Press, 2002, pp. 6275.

COSTA, Maria Cristina. Censura em Cena - Teatro e Censura no Brasil. São Paulo, EDUSP; FAPESP, 2006.

DESMET, Christy; SAWYER, Robert. Shakespeare and Appropriation. London; New York, Routledge, 1999.

GILBERT, Helen e TOMPKINS, Joanne. Post-colonial Drama. Theory, practice, politics. London; New York, Routledge, 1996.

GOMES, Eugênio. Shakespeare no Brasil. Ministério da Educação e Cultura/ Departamento de Imprensa Nacional, 1961.

GOMES, Celuta; AGUIAR, Thereza da Silva (org.). William Shakespeare no Brasil. Bibliografia das Comemoraçóes do Quarto Centenário - 1964. Rio de Janeiro, Divisão de Publicações e Divulgação da Biblioteca Nacional, Ministério da Educação e 
Cultura, 1965.

HELBO, André et al. Approaching Theatre. Bloomington and Indianapolis, Indiana University Press, 1987.

HOMEM, Rui Carvalho e Hoenselaars, Ton (org.). Translating Shakespeare for the Twenty-First Century. Amsterdam;New York, Editions Rodopi B.V., 2004.

HUTCHEON, Linda. A Theory of Adaptation. New York;London, Routledge, 2006.

KIDNIE, Margaret Jane. Shakespeare and the Problem of Adaptation. London;New York, Routledge, 2009.

KLIMAN, Bernice K.; SANTOS, Rick J. (org.). Latin American Shakespeares. Madison; Teaneck, Fairleigh Dickinson University Press, 2005.

MAROWITZ, Charles. Recycling Shakespeare. London, Macmillan, 1991.

MARTINS, Marcia Amaral Peixoto. Shakespeare em tradução no Brasil. In: SANTOS, Marlene Soares dos; LEÃO, Liana de Camargo (org.). Shakespeare, sua época e sua obra. Curitiba, Beatrice, 2008, pp. 301-19.

MARTINS, Marcia Amaral Peixoto. "Shakespeare no Brasil: Fontes de Referência e Primeiras Traduçóes". In: http://www.maxwell. lambda.ele.puc-rio.br/12701/12701.PDF. Acesso em: 23/10/2011.

O’SHEA, José Roberto. Early Shakespearean Stars Performing in Brazilian Skies: João Caetano and National Theater. In: KLIMAN, Bernice W; SANTOS, Rick J. (org.). Latin American Shakespeares. Madison; Teaneck, Fairleigh Dickinson University Press, 2005, pp. 25-36.

PRADO, Décio de Almeida. João Caetano: o ator, o empresário, o 
repertório. São Paulo, EDUSP; Perspectiva, 1972.

O resto é silêncio. In: O Estado de São Paulo, 13

Dec.1964, p. 21.

Teatro em Progresso. São Paulo, Perspectiva, 2002.

RAUEN, Margarida G. Brazil. In: DOBSON, Michael; WELLS, Stanley (org.). The Oxford Companion to Shakespeare. Oxford, Oxford UP, 2001, p. 54.

Shakespearean performance reviewing in Brazil. In: CAHIERS ÉLISABÉTHAINS, Special Issue, 2012, pp. 99-104.

Guilherme Schiffer Durães Caliban: From Canonical

Text to Resistance. In: KLIMAN, Bernice W; SANTOS, Rick J. (org.). Latin American Shakespeares. Madison; Teaneck, Fairleigh Dickinson University Press, 2005, pp. 130-142.

RESENDE, Aimara da Cunha (org.). Brazilian Readings of Shakespeare. Newark, University of Delaware Press, 2002.

ROCHA, Roberto Ferreira da. Hero or Villain: a Brazilian Coriolanus during the Period of the Military Dictatorship. In: KLIMAN, Bernice W; SANTOS, Rick J. (org.). Latin American Shakespeares. Madison; Teaneck, Fairleigh Dickinson University Press, 2005, pp. $37-53$.

ROCHA, Roberto Ferreira da. Hamlet com Cara de Brasil: Reverenciado, Questionado, Carnavalizado e Deglutido. In: CAMATI, A. S.; MIRANDA, C. A. (org.). Shakespeare sob múltiplos olhares. Curitiba, Ed. Solar do Rosário, 2009, pp. 291-297.

SANTOS, Marlene Soares dos. Theater for the Oppressed: Augusto Boal's A Tempestade. In: RESENDE, Aimara da Cunha (org.) Brazilian Readings of Shakespeare. Newark, University of Delaware Press, 2002, pp. 42-54. 
SANTOS, Marlene Soares dos; LEÃO, Liana de Camargo (org.).

Shakespeare, sua época e sua obra. Curitiba, Beatrice, 2008.

SHAKESPEARE, William. O primeiro 'Hamlet' in Quarto de 1603.

(trad. de José Roberto O’Shea). São Paulo, Hedra, 2010.

\section{ABSTRACT}

This paper addresses the reception of stage productions of Shakespeare's plays in Brazil. The lack of reviews during the 20th century is regarded as a result of the cultural policies of dictatorships, with restrictions to the freedom of speech and censorship. The predominance of reactionary critics until the 1980s and the emergence of reformist ones, with interdisciplinary approaches in the 1990s are considered.

\section{KEYWORDS}

culture; margin; performance criticism. 